\title{
Role of percutaneous cholecystostomy tube placement in the management of acute calculus cholecystitis in high risk patients
}

\author{
K. M. Inam Pal \\ Aga Khan university, inam.pal@aku.edu \\ Arif Ali \\ Aga Khan University, arif.ali@aku.edu \\ Hassaan Bari \\ Shaukat Khanum Memorial Cancer Hospital Lahore
}

Follow this and additional works at: https://ecommons.aku.edu/pakistan_fhs_mc_surg_orthop

Part of the Orthopedics Commons, and the Surgery Commons

\section{Recommended Citation}

Pal, K. I., Ali, A., Bari, H. (2018). Role of percutaneous cholecystostomy tube placement in the management of acute calculus cholecystitis in high risk patients. Journal of the College of Physicians and Surgeons Pakistan, 5(28), 386-389.

Available at: https://ecommons.aku.edu/pakistan_fhs_mc_surg_orthop/47 


\title{
Role of Percutaneous Cholecystostomy Tube Placement in the Management of Acute Calculus Cholecystitis in High Risk Patients
}

\author{
K.M. Inam Pal1, Arif Ali2 and Hassaan Bari3
}

\begin{abstract}
Objective: To evaluate the utility of percutaneous cholecystostomy tube in patients with acute calculus cholecystitis, who are considered unfit for immediate surgery.

Study Design: Observational study.

Place and Duration of Study: The Aga Khan University Hospital, Karachi, Pakistan, from January 2010 to December 2014.

Methodology: All adult patients who underwent percutaneous cholecystostomy tube placement for acute calculous cholecystitis were included. These patients were divided into two groups for further analysis. Group-I consisted those who had interval cholecystectomy after tube placement and Group-II were those who had no further treatment. Recurrence of symptoms, infections and operation related complications were noted.

Results: Sixty-five patients met the inclusion criteria. Mean age was 58.5 years. Forty-four patients $(67.7 \%)$ were males. Forty-three patients underwent interval cholecystectomy (Group-I) and 22 did not (Group-II). Mean operative time was $134.9 \pm 57.8$ minutes. Five $(11.6 \%)$ patients were converted to open cholecystectomy, two $(4.6 \%)$ developed CBD injury, and seven (16.2\%) developed surgical site infection. In Group-II, three patients (13.6\%) developed recurrence of symptoms and $19(86.4 \%)$ remained symptom-free. Catheter related problems occurred in four (18\%) patients. Mean follow-up was $19 \pm 8$ months.

Conclusion: Percutaneous cholecystostomy is a good alternative for patients unfit to undergo immediate surgery. Recurrence of symptoms after tube removal are in a low range; therefore, it can be considered a definitive management for high risk patients. Laparoscopic cholecystectomy after tube placement becomes technically challenging.
\end{abstract}

Key Words: Cholecystostomy tube. Laparoscopic cholecystectomy. CBD injury. Conversion rate. Acute cholecystitis. High-risk surgery. Symptom recurrence.

\section{INTRODUCTION}

Acute cholecystitis is one of the commonest surgical emergencies. In the majority of cases, a stone impacted in the neck of the organ is the cause; resulting in distension, subsequent inflammation and bacterial infection. Standard of care for patients presenting early in the course of their illness is an urgent surgical intervention, which is laparoscopic cholecystectomy. 1,2 However, immediate surgery may not be possible in some patients due to presence of significant or uncontrolled comorbidities making simple laparoscopic cholecystectomy, a high risk undertaking in such situations. ${ }^{3,4}$ In these circumstances, percutaneous tube cholecystostomy is used as a temporizing measure as it allows for source control of the infection without any increase risk of a major surgical intervention.5,6 At present, this can be done very effectively under ultrasound guidance.

1 Department of Surgery / Orthopedics², The Aga Khan University Hospital, Karachi.

3 Department of Surgical Oncology, Shaukat Khanum Memorial Cancer Hospital and Research Centre, Lahore.

Correspondence: Dr. Hassaan Bari, Senior Instructor, Surgical Oncology, Shaukat Khanum Memorial Cancer Hospital and Research Centre, Lahore.

E-mail:hassaan.bari@yahoo.com

Received: August 30, 2017; Accepted: December 22, 2017.
Combined with intravenous antibiotics, most of these patients can be managed successfully from the gallbladder infection perspective. Once the sepsis resolves, definitive treatment in case of calculous cholecystitis is still cholecystectomy. However, recent international literature suggests that percutaneous cholecystectomy may be a valuable option for definitive treatment in selected high-risk patients with acute calculous cholecystitis. 7,8 For patients having acalculous cholecystitis, tube cholecystostomy is considered definitive treatment; 8 nevertheless for calculous cholecystitis, it is still debatable as to the need of subsequent surgery after percutaneous tube cholecystostomy, its timing and whether interval surgery is technically more challenging. ${ }^{9}$

Only few studies have evaluated the efficacy and safety of percutaneous tube cholecystostomy in the treatment of acute cholecystitis, from this part of the world. ${ }^{10,11}$ Also none of these studies specifically divulged the role of percutaneous tube cholecystostomy in calculous cholecystitis. This study presents a retrospective review of patients, diagnosed to have acute calculous cholecystitis and treated with percutaneous cholecystostomy during a 5-year study period, at a tertiary care hospital in Pakistan.

The objective of this study was to evaluate the utility of percutaneous cholecystostomy tube in patients with 
acute calculus cholecystitis, who were considered unfit for immediate surgery.

\section{METHODOLOGY}

A retrospective chart review, from January 2010 to December 2014 was undertaken at the Aga Khan University Hospital, Karachi. The study proposal was exempted by the Hospital Ethical Review Committee (3743-Sur-ERC-15). All patients above 16 years of age, who were diagnosed to have acute calculus cholecystitis and underwent percutaneous cholecystostomy tube placement, were included in the study. Patients were identified by the medical records department using the ICD-9 coding system. Patients with cholecystostomy tube insertion were divided into two groups, i.e. those who had interval cholecystectomy within 6 - 8 weeks of tube placement were put in group I and those who had no further treatment were put in group II. The severity of cholecystitis was assessed according to Tokyo guidelines. ${ }^{12}$ The inflammatory process was graded into grades $\mathrm{I}, 2$ and 3 , according to the severity of inflammation and organ dysfunction.

Data was analysed using SPSS version 20. Qualitative variables were reported as percentages or proportions and Chi-square test was used for comparative analysis. Quantitative variables were reported as mean (standard deviation) and independent sample t-test was used for analysis. However, data which did not follow the normal distribution was reported as median (interquartile value) and Mann-Whitney U-test was used. A p-value of less than 0.05 was considered statistically significant.

\section{RESULTS}

Sixty-five patients were identified and included in the study. There were $44(67.7 \%)$ males and $21(32.3 \%)$ females. The mean age of patients was $58.5 \pm 12$ years. E. coli was the most common organism in bile cultures seen in $16(24.6 \%)$ patients. In $44(67.7 \%)$ patients, bile cultures were negative. Forty-one $(63.1 \%)$ patients were in the ASA III or IV category at presentation and 24 (36.9\%) were in the ASA II. Grade II was most common severity of cholecystitis, seen in $41(63.1 \%)$ cases, followed by grade III in 22 (34\%) patients. Patients were followed up for a mean of $19 \pm 8$ months in the medical or surgical outpatient clinics. All patients had their tubes removed as shown in Table I.

Forty-three patients (Group I) underwent an interval cholecystectomy. The remaining 22 (Group II) were managed non-operatively; of these, 3 patients expired during their index admission and were excluded from further analysis.

All 43 patients in Group I had attempted laparoscopic cholecystectomy. In five patients, this had to be converted to an open procedure due to difficult dissection, giving a conversion rate of $11 \%$. The median
Table I: Demographics.

\begin{tabular}{l|c}
\hline Variable & $\begin{array}{c}\mathrm{N}=65 \\
\mathrm{n}(\%)\end{array}$ \\
\hline Age ${ }^{\text {(year) }}$ & $58.5 \pm 12.6$ \\
\hline Gender & $44(67.7)$ \\
Male & $21(32.3)$ \\
Female & $53(81.5)$ \\
\hline Comorbids & $38(58.5)$ \\
DM II & $33(50.8)$ \\
Hypertension & $15(23.1)$ \\
Ischemic heart disease & $6(9.2)$ \\
CKD & $14(21.5)$ \\
Other comorbids & $24(36.9)$ \\
\hline ASA level & $41(63.1)$ \\
I / II & $5(4-7)$ \\
III / IV & \\
\hline Hospital stay ${ }^{* *}$ (days) & $5(7.7)$ \\
\hline Grade of acute cholecystitis & $39(60.0)$ \\
I & $21(32.3)$ \\
II & $19 \pm 8$ \\
III & $44(67.7)$ \\
\hline Follow-up* (months) & \\
\hline Cholecystogram & \\
\hline${ }^{*}$ mean, standard deviation; ${ }^{* *}$ median, (interquartile value). & \\
\hline &
\end{tabular}

"mean, standard deviation; ${ }^{* *}$ median, (interquartile value).

Table II: Comparison of Group I and II.

\begin{tabular}{|c|c|c|c|}
\hline Variable & $\begin{array}{c}\text { Group I } \\
\mathrm{N}=43 \\
\mathrm{n}(\%)\end{array}$ & $\begin{array}{c}\text { Group II } \\
\mathrm{N}=22 \\
\mathrm{n}(\%)\end{array}$ & $p$-value \\
\hline $\mathrm{Age}^{*}$ (years) & $55.3 \pm 11.4$ & $64 \pm 11.5$ & 0.006 \\
\hline \multicolumn{4}{|l|}{ Gender } \\
\hline Male & $31(72.1)$ & $13(59.1)$ & 0.401 \\
\hline Comorbid & $35(81.4)$ & $18(81.8)$ & 1.000 \\
\hline \multicolumn{4}{|l|}{ ASA Level } \\
\hline III or IV & $24(55.8)$ & $17(77.3)$ & 0.109 \\
\hline \multicolumn{4}{|l|}{ Grade of acute cholecystitis } \\
\hline Grade I or II & $31(72.1)$ & $13(59.1)$ & 0.401 \\
\hline Grade III & $12(27.9)$ & $9(40.9)$ & \\
\hline $\begin{array}{l}\text { Duration of tube placement }{ }^{\star \star} \\
\text { (days) }\end{array}$ & $45(40-58)$ & $38(26.25-57)$ & $0.068, U=306$ \\
\hline Hospital stay** (days) & $5(4-7)$ & $5.5(4-9.25)$ & $0.253, U=391$ \\
\hline
\end{tabular}

operative time was 120 minutes (interquartile range = 91-75 minutes). Two patients had CBD injuries during laparoscopic procedure $(4.5 \%)$. One was managed with intraoperative CBD repair over T-tube, the other with post-procedure ERCP and stenting. Seven patients developed surgical site infection.

Of the 19 patients in Group II, during follow-up, three developed symptoms that needed intervention. Two patients had attacks of pancreatitis, one at 6th month and the other in the 2nd year. One needed an ERCP and laparoscopic cholecystectomy; the other was managed with ERCP and papillotomy alone. The third patient developed acute cholecystitis 4 years after removal of tube. This was managed successfully with antibiotics as the patient refused intervention.

On comparing the two groups apart from age (Group I=55.3 vs. Group $\|=64$ years, $p=0.006$ ), no other significant 
difference was found with regard to gender, comorbids, ASA level, grade of acute cholecystitis, duration of tube placement, and hospital stay (as shown in Table I).

\section{DISCUSSION}

For the majority of patients presenting with acute calculus cholecystitis, an urgent laparoscopic cholecystectomy would be the treatment of choice. ${ }^{2}$ In patient deemed unfit to undergo immediate surgery, due to associated medical conditions, the acute infection can be successfully aborted in over $90 \%$ of cases by percutaneous tube decompression of the distended gallbladder and judicious antibiotic usage.

The need for an interval cholecystectomy in acute calculus cholecystitis, successfully treated non-operatively, is unclear. There are no randomised studies addressing this area, the general consensus of opinion in literature being that surgery is offered to patients fit to undergo the procedure. In patients having acalculus acute cholecystitis, tube cholecystostomy can be used as definitive treatment. 8

In this study, $65 \%$ of patients with acute calculus cholecystitis initially managed with a percutaneous tube cholecystostomy, subseqently underwent surgery. All had attempted a laparoscopic procedure. In $89 \%$, the procedure was successfully completed as planned. In $11 \%$, the procedure had to be converted due to dense adhesions and distorted anatomy. The expected conversion rate for elective laparoscopic cholecystectomy is about $1-4 \% .{ }^{13,14}$ The average procedure time for this group was also more than expected for elective procedures on the gallbladder $130 \pm 58$ minutes compared to average time in literature of $60-90$ minutes. Similarly, the incidence of CBD injury in this group was $4.8 \%(2 / 44)$, a proportion much higher than seen in elective gallbladder surgeries. ${ }^{15}$

Out of the 19 patients in group II, 15.7\% (3/19) developed symptoms related to gallstones. In two, interventions were needed, the third successfully managed with antibiotics. In a retrospective review, it is not possible to identify the exact reason why elective surgery was not offered in this group but it is probably safe to presume that the patients' health status and willingness to undergo the operation were important factors.

In literature the proportion of this subgroup, i.e. who relapse after tube removal, is variable from $10-40 \% .16,17$ There are no seemingly identifiable risk factors for relapse at present that could form the basis for selective intervention in this group. For the present, it appears as if the decision to operate was based on the subjective assessment of the involved surgeon and the fitness of a given patient to undergo surgery. There is an accumulating evidence in literature albeit at present of a weak nature, that the proportion relapsing with significant symptoms may not be large. ${ }^{16,18-20}$ This area needs prospective randomised trials to guide the decision-making process in these cases.

Acute cholecystitis presenting in patients with uncontrolled medical conditions can be effectively managed with radiologically placed percutaneous tube cholecystostomy and antibiotics in over $90 \%$ of cases. Patients offered subsequent elective surgery need to be counselled as to the likely difficult nature of the operation, its higher incidence of conversion to an open procedure, and complication rate.

\section{CONCLUSION}

Percutaneous cholecystostomy is a good alternative for patients unfit to undergo immediate surgery. Recurrence of symptoms after tube removal are in a low range; therefore, it can be considered a definitive management for high risk patients. Laparoscopic cholecystectomy after tube placement becomes technically challenging.

\section{REFERENCES}

1. Wiseman JT, Sharuk MN, Singla A, Cahan M, Litwin DE, Tseng JF, et al. Surgical management of acute cholecystitis at a tertiary care center in the modern era. Arch Surg 2010; 145: 439-44.

2. Wu XD, Tian X, Liu MM, Wu L, Zhao S, Zhao L. Meta-analysis comparing early versus delayed laparoscopic cholecystectomy for acute cholecystitis. Br J Surg 2015; 102:1302-13.

3. Cull JD, Velasco JM, Czubak A, Rice D, Brown EC. Management of acute cholecystitis: prevalence of percutaneous cholecystostomy and delayed cholecystectomy in the elderly. J Gastrointest Surg 2014; 18:328-33.

4. Cherng N, Witkowski ET, Sneider EB, Wiseman JT, Lewis J, Litwin DE, et al. Use of cholecystostomy tubes in the management of patients with primary diagnosis of acute cholecystitis. J Am Coll Surg 2012; 214:196-201.

5. Leveau P, Andersson E, Carlgren I, Willner J, Andersson R. Percutaneous cholecystostomy: a bridge to surgery or definite management of acute cholecystitis in high-risk patients? Scand J Gastroenterol 2008; 43:593-6.

6. Bakkaloglu H, Yanar H, Guloglu R, Taviloglu K, Tunca F, Aksoy M, et al. Ultrasound guided percutaneous cholecystostomy in high-risk patients for surgical intervention. World J Gastroenterol 2006; 12:7179-82.

7. Bala M, Mizrahi I, Mazeh H, Yuval J, Eid A, Almogy G. Percutaneous cholecystostomy is safe and effective option for acute calculous cholecystitis in select group of high-risk patients. Eur J Trauma Emerg Surg 2016; 42:761-6.

8. Kirkegard J, Horn T, Christensen SD, Larsen LP, Knudsen AR, Mortensen FV. Percutaneous cholecystostomy is an effective definitive treatment option for acute acalculous cholecystitis. Scand J Surg 2015; 104:238-43.

9. Mizrahi I, Mazeh H, Yuval JB, Almogy G, Bala M, Simanovski N, et al. Perioperative outcomes of delayed laparoscopic cholecystectomy for acute calculous cholecystitis with and without percutaneous cholecystostomy. Surgery 2015; 158: 728-35.

10. Saeed SA, Masroor I. Percutaneous cholecystostomy (PC) in 
the management of acute cholecystitis in high risk patients. $J$ Coll Physicians Surg Pak 2010; 20:612-5.

11. Nasim S, Khan S, Alvi R, Chaudhary M. Emerging indications for percutaneous cholecystostomy for the management of acute cholecystitis - a retrospective review. Int J Surg 2011; 9:456-9.

12. Takada T, Strasberg SM, Solomkin JS, Pitt HA, Gomi H, Yoshida M, et al. TG13: Updated Tokyo Guidelines for the management of acute cholangitis and cholecystitis. $J$ Hepatobiliary Pancreat Surg 2013; 20:1-7.

13. Livingston $\mathrm{EH}$, Rege RV. A nationwide study of conversion from laparoscopic to open cholecystectomy. Am J Surg 2004; 188:205-11.

14. Tang B, Cuschieri A. Conversions during laparoscopic cholecystectomy: risk factors and effects on patient outcome. J Gastrointest Surg 2006; 10:1081-91.

15. Connor S, Garden OJ. Bile duct injury in the era of laparoscopic cholecystectomy. Br J Surg 2006; 93:158-68.
16. Suzuki K, Bower M, Cassaro S, Patel RI, Karpeh MS, Leitman IM. Tube cholecystostomy before cholecystectomy for the treatment of acute cholecystitis. JSIS 2015; 19:e2014.

17. McKay A, Abulfaraj M, Lipschitz J. Short- and long-term outcomes following percutaneous cholecystostomy for acute cholecystitis in high-risk patients. Surg Endoscop 2012; 26: 1343-51.

18. Chang YR, Ahn YJ, Jang JY, Kang MJ, Kwon W, Jung WH, et al. Percutaneous cholecystostomy for acute cholecystitis in patients with high comorbidity and re-evaluation of treatment efficacy. Surgery 2014; 155:615-22.

19. Zarour S, Imam A, Kouniavsky G, Lin G, Zbar A, Mavor E. Percutaneous cholecystostomy in the management of highrisk patients presenting with acute cholecystitis: Timing and outcome at a single institution. Am J Surg 2017; 214:456-61.

20. Papis D, Khalifa E, Bhogal R, Nair A, Khan S, Hamady Z, et al. Is percutaneous cholecystostomy a good alternative treatment for acute cholecystitis in high-risk patients? Am Surg 2017; 83: 623-7. 